\title{
Spring wheat varieties resistance to the common root rot
}

Sukhomlinov V.Yu. ${ }^{1,3 *}$, Toropova E.Yu. ${ }^{1,2}$

${ }^{1}$ Novosibirsk State Agrarian University, Novosibirsk, Russia

${ }^{2}$ All-Russian Research Institute of Phytopathology, Moscow region, Russia

${ }^{3}$ Siberian Research Institute of Plant Production and Breeding - Branch of the Institute of Cytology and Genetics, SB RAS, Novosibirsk, Russia

*email: plantdef@bionet.nsc.ru

The purpose of the research was to identify resistant to the common root rot (Helminthosporium sativum Sacc.) spring wheat varieties from the collection of the Institute of Cytology and Genetics. The studies were carried out in 2020-2021 in the northern forest-steppe of the Ob region (West Siberia) using generally accepted methods. Among 15 varieties of spring wheat collection from different regions of Russia and countries of the world, no varieties were found that were not affected by common root rot. The zonal threshold of root rot harmfulness was exceeded to 3 times at the seedlings stage, and 3.7 times at the end of the growing season. The $H$. sativum part in the pathogenic complexes of spring wheat varieties root rot was $10-50 \%$ at the germination phase and $9-30 \%$ at the maturity phase. The rest of the pathogenic complexes were Fusarium Link. fungi. The varieties had a significant effect on $H$. sativum propagation on the basal leaves; the difference in the reproduction rate of the micromycete was 19 times for the varieties. By the end of the growing season, the H. sativum conidia population in the varieties rhizosphere soil increased by up to 55 times in comparison with the beginning of the growing season. The correlation coefficient between the $H$. sativum reproduction intensity on basal leaves and the conidia number in the soil was $R=0.890 \pm 0.127$ ( $p<0.01)$. The varieties were divided into groups according to their ability to stabilize the phytosanitary state of the soil: "altruists", limiting the development of foci of H.sativum in the soil (Sibirskaya 17, Zauralochka, Tobolskaya and Quarna), "egoists", significantly worsening the phytosanitary state of the soil for subsequent crops (Remus, Jin Chun 2 and K-65834), "neutral", occupying an intermediate position.

Acknowledgements: The reported study was funded by RFBR, project number 20-31690008. 